\title{
Data Analytics of Social Networking sites using Game Theory Model
}

\author{
Satyajit S. Uparkar, Khushbu R. Asati, Prachi U. Sahahare, Nalini V. Vaidya
}

\begin{abstract}
Decision making tools provides substantial supports to companies as to optimize their strategies with respect to their competitors. The end users or say the consumers' satisfaction plays the key role in the Decision making. The application under this research work is based on two giants of the social networking sites viz Facebook and Instagram. The primary requirement of a Game theory model is to have such competitors or says players and their interaction parameters. The first step is to identify the common features between these two players which satisfy the interaction criterion. These are the called interactive strategies under consideration. A heterogeneous group of frequent users of these two social networking sites is selected using simple random sampling. The reliability of the questionnaire, formed on the basis of interactive parameters, is tested by using Cronbach's alpha test. The graphical and descriptive statistics give the initial trends of the end users. The regression analysis is carried out where the intercept data is collected as payoff values. This leads to the formation of the two player Game theory model. As the final result, the optimum strategies of each player and the value of the game are calculated. The interpretation of the calculated values reflects the influence of decision making for the optimum strategies under the game theory model.
\end{abstract}

Index Terms: Game theory, Interactive strategies, Optimum strategies, Value of the game.

\section{INTRODUCTION}

Any business situation involves competition. Effective decision making plays a vital role in such situations mainly because decision will have direct impact on the revenue earning potentials of business organizations. People share knowledge, experience and thoughts with the world by using social media like Facebook, Instagram, Twitter, Blogs etc. This has changed the trend in which people are communicating and influencing the social, political and economical behavior of others. The social network perspective provides various methods for analysis of the structure of the social entities and also variety of theories explaining the patterns within these structures.

Revised Manuscript Received on 14 September, 2019.

Satyajit S. Uparkar, Department of Computer Application, Shri Ramdeobaba College of Engineering and Management, Nagpur, India, uparkarss@rknec.edu

Khushbu R. Asati, Department of Computer Application, Shri Ramdeobaba College of Engineering and Management, Nagpur, India, asatikr@rknec.edu

Prachi U. Sahahare, Department of Computer Application, Shri Ramdeobaba College of Engineering and Management, Nagpur, India, shaharepu@rknec.edu

Nalini V. Vaidya, Department of Applied Mathematics, G. H. Raisoni College of Engineering, Nagpur, India, nalini.vaidya@ raisoni.net
According to the prediction given by Edison Research states that by 2020, Instagram will overtake Facebook in total usage. This can be thought of two strong competitors in the domain of social media.

The objective of this research work is to build a game theory model on basis of common features of Facebook and Instagram. The analysis of the end result is to determine which feature among all the features is better as compared to other. The value of the game provides the win-win situation for the two competitors.

The seven common features in both Facebook and Instagram are-

- Chatting Interface

- Live Videos

- Private or Public account

- Stories

- Like and Comment

- Group Created

- Security

These seven common features satisfy the basic assumption of the game theory for having interaction between Facebook and Instagram. In terms of game theory, Facebook and Instagram are called as two players. The common features are noted as the strategies. To build a game theory model, the payoff values are required. The data regarding these payoff values are generated by responses of questionnaire of the above mentioned features.

The section wise walk through of this research work is-Section II is the Literature review where the base of building the game theory model is discussed. Section III is of the Research Methodology in which step by step details of the approach is discussed. Section IV is about the actual work of Data Analytics, where the graphical tool, statistical tool and decision making tool are implemented to provide the end results. Section V is the highlights of the interpretations of all the end results with the conclusion. The last section is the list of references useful for this research work.

\section{LITERATURE REVIEW}

Initially the major work in the domain of social networking and then the aspect of game theory was the focus of the literature survey. [1] This paper demonstrates gratifications theory, its importance and usages in social media. It also provides a comprehensive understanding for consumers' usages of social media. [2] This paper is about the first comprehensive literature survey in the domain of social media research. It also reflects a better understanding of the causes and effects of the adoption and usage of social media. [3]. 
This blog provides survey statistics conducted by YouGov-Mint that till August 2018 there were $85 \%$ users of Instagram who also use Facebook whereas $71 \%$ users of Facebook who also use Instagram. [4] This blog by NapoleonCat provides the statistics till June 2019, for the current users of Facebook and Instagram. In India, 18.6\% of its entire populations are the Facebook users, whereas $4.8 \%$ of Indian population is Instagram users. [5] In this paper it was examine the content of for-profit organizations' Facebook pages and how the communication strategy employed impacts stakeholders' perceptions of the organization-public relationship, corporate social responsibility, attitudes, and purchase intent. [6] This exploratory study contributes a fundamental knowledge about Instagram and social networking communication with a theoretical stance. [7] In this authors have explained how the text, tables, and graphs are effective communication media that present and convey data and information that helps in understanding the content of research. [8] Talks about emergence of experimental game theory that can be used to traced two factors - the need for empirical information about principles of strategic behavior and the advantages of experiments in providing it. [9] In this paper the author has review game theory and innovation related papers published in the past three decades. [10] Game theory model is a system in which multiple decision makers act according to their own objectives and where individual choices can affect system outcomes. [11] This paper is an application of a game theory model with an objective to develop the optimal strategy for innovative products manufacturing at the enterprise level.

The above mentioned papers lead the path to find out the solution for the two giants of the social media by using the concept of game theory model.

\section{RESEARCH METHODOLOGY}

Research Methodology provides an analytical approach to solve a research problem. This section includes the following steps-

1) Preparation of the questionnaire based on the purpose of the research work- Here a Google form was designed to have the demography information of the respondents. In addition 14 questions were framed on the common features of the two competitors. 10 point linear scale was used to collect the data from the respondents. Every field was compulsory before submitting the online form. The advantage of the online form violates the presence of outliers and hence the validation of the data is satisfied.

2) Identify the scope as to collect the data from the responses given by the end users- A simple random sample technique was used to collect the data. A sample size of 100 was used on a heterogeneous group of respondents. These violets any prejudice related to any features.

3) Conduction of Pilot survey to satisfy the reliability of the questionnaire model as per the purpose of the research work- Initial sample of 20 respondents was collected for the Pilot survey. Cronbach's alpha reliability test was carried out in three ways.

4) Graphical Representation- After the successful completion of the reliability test, remaining 80 respondents were approached. Before preparing the bar graph, the 10 point scale data was transform into five ordinal categories. 1-2: Sufficient, 3-4: Satisfactory, 5-6: Good, 7-8: Very Good and 9-10: Excellent. The general trends of the respondents can be identified by use of the graphical tools.

5) Descriptive statistics- The average value and standard deviation were calculated, as to identify the comparative figures and the consistency of the features.

6) Regression analysis- The concept of simple regression analysis is used in two ways: $\mathrm{Y}$ on $\mathrm{X}$ and $\mathrm{X}$ on $\mathrm{Y}$. The output of regression analysis provides two parts i.e. Intercept which determine the by default value of $Y$ when $X=0$. This is the point of interest for collecting the payoff values. The other part is the slope which determines the positive or negative impact of the independent variable on the dependent variable. This is not the concern for the formation of the game theory model.

7) Game theory model- On the basis of the intercept data collected from the above two processes of $Y$ on $X$ and $X$ on $\mathrm{Y}$, payoff matrix of $7 \mathrm{x} 7$ in form of $\left(\mathrm{a}_{\mathrm{x} i}, \mathrm{a}_{\mathrm{yj}}\right)$ for the $(\mathrm{i}$, j) cell can be inserted.

8) Solution of the Game theory model-Firstly keeping player A as major and player B as minor, all the first entries $\mathrm{a}_{\mathrm{xi}}$ among $\left(\mathrm{a}_{\mathrm{xi}}, \mathrm{a}_{\mathrm{yj}}\right)$ are considered to find the value of the game and optimum strategies of the game. On the other side, keeping player B as major and player B as minor, all the second entries $\mathrm{a}_{\mathrm{yj}}$ among $\left(\mathrm{a}_{\mathrm{xi}}, \mathrm{a}_{\mathrm{yj}}\right)$ are considered to find the value of the game and optimum strategies of the game. The transpose of the original matrix values for $\mathrm{a}_{\mathrm{yj}}$ are taken to solve for the player $\mathrm{B}$.

9) The final fact and figures can be reflected as the end results for both the players of the game theory.

The details of point 2 to point 9 are discussed in the following section of Data Analysis.

\section{DATA ANALYSIS}

The process of transformation data into the valuable and comparable information is performed using Data Analysis. The focus of this research renders around the responses which can build a game theory model. The end results can provide the stand for selecting the optimum strategies using the decision making tool like the Game theory model. Step wise approach for data analysis is given below-

\section{Base for sample size}

Taking the facts and figure available for users of Facebook and Instagram in India [3],[4] an estimated population size of the common users in the year 2019 is about 5,64,14,500. For an exploratory research based on consumer survey, the margin of error can be extended to $10 \%$ [12]. Keeping by default value of confidence level at $95 \%$ and for response of distribution at $50 \%$, the sample size come to be 97 . 
The approximation for round off value to be taken for this research work was finalized as 100 samples. The stakeholders of our college were provided the questionnaire using Google form to collect the relevant data.

\section{Cronbach's alpha reliability test} of reliability in the social and organizational sciences [13],[14]. To identify the reliability of the model, a pilot survey using an initial sample of 20 respondents was conducted. The respondents of this initial sample were the stakeholders of our college situated at Nagpur. Cronbach's alpha values based on the responses for of all 7 features for Facebook, Instagram respectively and also for both of them as to find the overall status of the model, are given in the Table-I.

Table- I: Reliability test for Pilot survey

\begin{tabular}{|c|c|c|c|c|c|}
\hline $\begin{array}{c}\text { Sr. } \\
\text { No. }\end{array}$ & Index & $\begin{array}{c}\text { No. of } \\
\text { Items }\end{array}$ & $\begin{array}{c}\text { Initial } \\
\text { Sample } \\
\text { Size }\end{array}$ & $\begin{array}{c}\text { C. alpha } \\
\text { value }\end{array}$ & Indication \\
\hline 1 & Facebook & 7 & 20 & 0.917 & Excellent \\
\hline 2 & Instagram & 7 & 20 & 0.924 & Excellent \\
\hline 3 & $\begin{array}{c}\text { Facebook and } \\
\text { Instagram }\end{array}$ & 14 & 20 & 0.903 & Excellent \\
\hline
\end{tabular}

Interpretation of Table-I: Since all the three Cronbach's alpha values are greater than 0.90 , the questionnaire is excellent one for carrying this research work. The model is reliable to conduct the survey for the remaining samples.

\section{Graphical representation}

This section is divided in two sub-sections as given below-

\section{i. Demographic Information}

As per the domain of social networking sites, demographic feature of occupation can be an influencing factor[15]. The sample distribution of the heterogeneous groups is given in Fig.1.

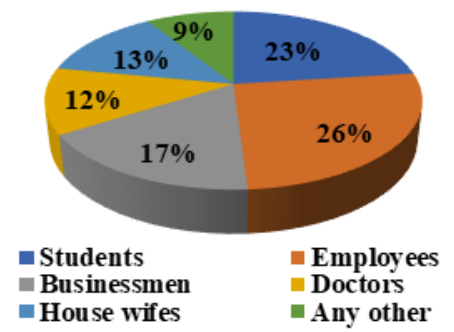

Fig. 1. Sample Distribution based on Occupation

Interpretation of Fig. 1: Almost $50 \%$ of the sample is shared by Students and employees. Remaining are included in the next $50 \%$. The variety of the demographic information based on occupation, reflects the heterogeneity and hence violets any prejudice related to any of the features.

\section{ii. Trend within the responses}

As mentioned earlier the data was transformed into 5 different ordinal categories [16],[17]. The general trend can be identified from the responses by using the stack bar chart.
Cronbach's alpha is one of the most widely used measures

Fig. 2, provides the information regarding the various features of both the competitors.

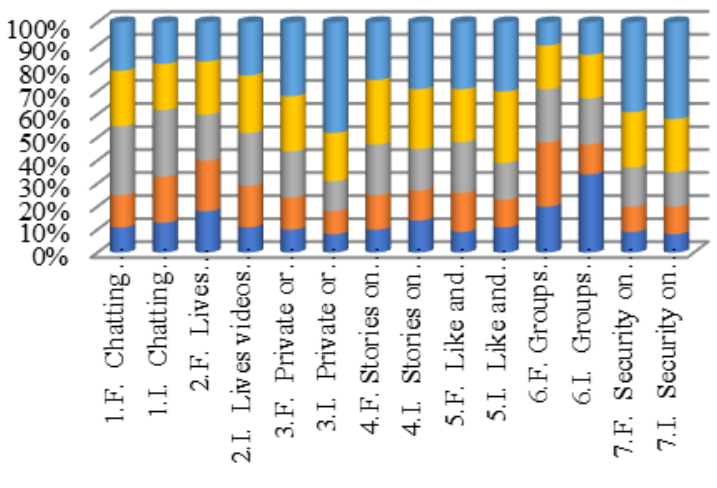

- Sufficient $\square$ Satisfactory $\square$ Good $\square$ Very Good $\square$ Excellent

Fig. 2. Trends of responses on the seven features for the two players

Interpretation of Fig. 2: Chatting Interface of Facebook is better as compared to Instagram. On the other hand live videos on Instagram are more liked by the end users as compared to the live videos of Facebook. Private or public account on Facebook share more contribution as compared to Instagram accounts. Stories as well as like and comments of both Facebook and Instagram are liked by the end user. The features of group created on both the sites are not as per the satisfaction level. The security feature stands highest in case of both the social networking sites.

\section{Descriptive statistics}

The measure of central tendency and the dispersion within the data help to find out the general trend. The ratio of Standard deviation and the Average value indicates the consistency among the perception of the respondents towards Facebook and Instagram. Following table provides the consistency levels for each of the features among each of the Players.

Table- II: Player wise Descriptive statistics for various features

\begin{tabular}{|c|c|c|c|c|c|}
\hline Players & Features & Average & $\begin{array}{c}\text { Std. } \\
\text { Dev. }\end{array}$ & $\begin{array}{c}\text { Coeff. of } \\
\text { Variation } \\
(\%)\end{array}$ & $\begin{array}{c}\text { Consistent } \\
\text { by Ranking }\end{array}$ \\
\hline \multirow{5}{*}{ Facebook } & $\begin{array}{c}\text { Chatting } \\
\text { Interface }\end{array}$ & 6.02 & 2.61 & 43.34 & 5 \\
\cline { 2 - 6 } & Live videos & 5.50 & 2.85 & 51.78 & 6 \\
\cline { 2 - 6 } & $\begin{array}{c}\text { Private or } \\
\text { Public }\end{array}$ & 6.57 & 2.83 & 43.12 & 4 \\
\cline { 2 - 6 } & $\begin{array}{c}\text { Stories } \\
\text { Like and } \\
\text { Comments }\end{array}$ & 6.41 & 2.56 & 39.93 & $2 * *$ \\
\cline { 2 - 6 } & $\begin{array}{c}\text { Group } \\
\text { Created }\end{array}$ & 4.83 & 2.66 & 55.14 & 7 \\
\cline { 2 - 6 } & $\begin{array}{c}\text { Security } \\
\text { Instagram }\end{array}$ & 6.90 & 2.75 & 39.92 & $1 *$ \\
\cline { 2 - 6 } & $\begin{array}{c}\text { Chatting } \\
\text { Interface }\end{array}$ & 5.62 & 2.57 & 45.79 & 5 \\
\cline { 2 - 6 } & Live videos & 6.25 & 2.78 & 44.53 & 4 \\
\cline { 2 - 6 } & $\begin{array}{c}\text { Private or } \\
\text { Public }\end{array}$ & 7.38 & 2.78 & 37.68 & $1 * 35$ \\
\hline
\end{tabular}




\begin{tabular}{|c|c|c|c|c|c|}
\hline Players & Features & Average & $\begin{array}{c}\text { Std. } \\
\text { Dev. }\end{array}$ & $\begin{array}{c}\text { Coeff. of } \\
\text { Variation } \\
(\%)\end{array}$ & $\begin{array}{c}\text { Consistent } \\
\text { by Ranking }\end{array}$ \\
\hline \multirow{7}{*}{} & Stories & 6.38 & 2.98 & 46.67 & 6 \\
\cline { 2 - 6 } & $\begin{array}{c}\text { Like and } \\
\text { Comments }\end{array}$ & 6.68 & 2.84 & 42.44 & 3 \\
\cline { 2 - 6 } & $\begin{array}{c}\text { Group } \\
\text { Created }\end{array}$ & 4.81 & 3.15 & 65.46 & 7 \\
\cline { 2 - 6 } & Security & 7.15 & 2.90 & 40.61 & 2 2** \\
\hline
\end{tabular}

Interpretation of Table -II: Security of Facebook is most consistent where as Stories is next consistent among all its features. On the other hand Private or Public account of Instagram is most consistent whereas Security is next among all its features. Group created found to be least consistent among the two players. Security in both cases is the consistent features which plays important role in the domain of social networking sites.

\section{Game theory model}

After carrying the regression analysis, the intercept payoff matrix for both the players is given below. Thus it is a $7 \times 7$ game theory model on a non-cooperative basis as these players do not share their internal policies[10]. The common features are the interaction points between these two players.

Table- III: Formation of 7x7 Game theory model

\begin{tabular}{|c|c|c|c|c|c|c|c|c|}
\hline \multirow{2}{*}{\multicolumn{2}{|c|}{ Features }} & \multicolumn{7}{|c|}{ Player B (Instagram) } \\
\hline & & $\begin{array}{l}\text { Chatting } \\
\text { Interface }\end{array}$ & Live videos & $\begin{array}{c}\text { Private or } \\
\text { Publicic }\end{array}$ & Stories & $\begin{array}{l}\text { Like and } \\
\text { Comonents }\end{array}$ & $\begin{array}{l}\text { Group } \\
\text { Created }\end{array}$ & Seccurity \\
\hline \multirow{7}{*}{$\begin{array}{l}\text { Player A } \\
\text { (Facebook) }\end{array}$} & $\begin{array}{l}\text { Chatting } \\
\text { Interface }\end{array}$ & $(5.52,5.10)$ & $(4.79,4.91)$ & $(5.29,6.70)$ & $(5.51,5.75)$ & $(6.26,6.93)$ & $(5.74,4.31)$ & $(5.41,6.51)$ \\
\hline & Live videos & $(4.23,4.61)$ & $(3.97,4.97)$ & $(3.86,6.22)$ & $(5.25,6.15)$ & $(5.48,6.66)$ & $(5.12,4.28)$ & $(6.15,7.67)$ \\
\hline & 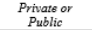 & $(5.50,4.59)$ & $(4.84,4.49)$ & $(3.67,4.90)$ & $(6.14,5.90)$ & $(5.84,5.96)$ & $(5.73,3.39)$ & $(6.20,6.79)$ \\
\hline & Stories & $(5.80,4.91)$ & $(5.87,5.50)$ & $(5.57,6.53)$ & $(5.42,5.03)$ & $(5.67,5.81)$ & $(5.95,3.87)$ & $(6.13,6.83)$ \\
\hline & $\begin{array}{l}\text { Like and } \\
\text { Comments }\end{array}$ & $(5.09,4.07)$ & $(4.87,4.38)$ & $(5.66,6.53)$ & $(5.13,4.60)$ & $(4.31,4.26)$ & $(5.54,2.91)$ & $(6.16,6.71)$ \\
\hline & Group Created & $(3.57,4.61)$ & $(2.57,4.34)$ & $(2.89,5.99)$ & $(2.89,4.54)$ & $(2.74,4.97)$ & $(2.63,1.72)$ & $(4.88,7.19)$ \\
\hline & Security & $(6.23,4.90)$ & $(6.52,5.82)$ & $(5.50,6.05)$ & $(6.93,6.42)$ & $(7.26,7.08)$ & $(7.19,5.36)$ & $(4.83,4.93)$ \\
\hline
\end{tabular}

Interpretation of Table -III: All the values of the intercepts are positive. Most of the values revolve 5 to 7 indicating good bonding of cell values. On the other hand values between 1 to 3 , indicate week bonding of cell values.

\section{Solution of Game theory model}

Matrix Game solver provides the online facility for solving matrix game as a matrix where Player I choose a row and simultaneously Player II choose a column. The matrix entry of the jointly selected row and column represents as usual the winnings of the row chooser and the loss of the column chooser.

Case 1: Keeping player A as major (row chooser) and player B as minor (column chooser), the game can be solved as -

The matrix is

5.524 .795 .295 .516 .265 .745 .41

4.233 .973 .865 .255 .485 .126 .15

5.504 .843 .676 .145 .845 .736 .20

5.805 .875 .575 .425 .675 .956 .13

5.094 .875 .665 .134 .315 .546 .16

3.572 .572 .892 .892 .742 .634 .88

6.236 .525 .506 .937 .267 .194 .83

The solution is: The value is 5.59 .

An optimal strategy for Player A (Facebook) is:

$(0,0,0,0.02935,0.55025,0,0.4204)$
An optimal strategy for Player B (Instagram) is: (0.07944, 0, 0.90232, 0, 0.01824, 0, 0)

Case 2: Keeping player B as major (row chooser) and player A as minor(column chooser), the game can be solved as-

The matrix is

5.104 .614 .594 .914 .074 .614 .90

4.914 .974 .495 .604 .384 .345 .82

6.706 .224 .906 .536 .535 .996 .05

5.756 .155 .905 .034 .604 .546 .42

6.936 .665 .965 .814 .264 .977 .08

4.314 .283 .393 .872 .911 .725 .36

6.517 .676 .796 .836 .717 .194 .93

The solution is: The value is 5.93 .

An optimal strategy for Player B(Instagram) is: $(0,0,0.32607,0,0.29481,0,0.37912)$

An optimal strategy for Player A( Facebook) is: $(0,0,0.23636,0,0.31427,0,0.44937)$

Interpretation of Solutions of games: The value of the game in both cases lies between 5 to 6 , which is good enough for both the players. In both cases optimum strategies are three for both players.

In case 1 where Facebook dominant Instagram features like stories, likes and comments and security provide optimum strategies Likes and comments, shares the major contribution. On the other hand features like Chatting Interface, private and public account and likes and comments provide optimum strategies for Instagram against Facebook. Here major contribution is shared by Private and public feature.

In case 2, where Instagram dominates Facebook, features like Private or public account, Stories and security provide the optimum strategies. Finally in such situation same features are the optimum strategies for Facebook. In both cases Security features shares major contribution.

\section{CONCLUSION}

Thus the proper flow and proper use of data analytical tools are sufficient to provide a beneficial and feasible solution. The highlights of this research work are-

1) The reliability of model for all the seven features has been excellent as per the Cronbach's alpha test.

2) The facts and figures using graphical tools and descriptive statistics are good enough and mark above the average values for all the seven features under consideration.

3) Group created found to be least consistent among the two players. The security feature for Facebook where as Private and public account feature for Instagram, were most consistent as compared to their other features. The enchantment of these features on the respective platforms thus can provide more privacy to the end users.

4) Regression analysis carried for both the players provide the positive intercepts and are used as the payoff values for construction of a 7x7 non-cooperative game.

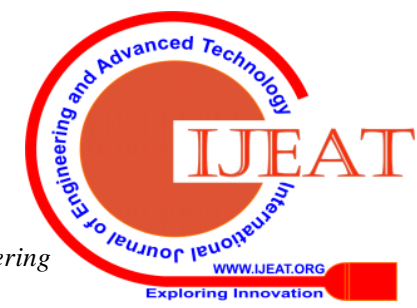


5) The value of the game in both the cases is above average value that provides the win-win situation and is good enough for both the competitors. This shows that the end users are satisfied by the common features of these two social networking sites.

6) It can be observed that features of Instagram share highest among all the strategies even under the dominance of Facebook. On the other hand Instagram dominating to Facebook reflect same features as their optimum strategies.

Game theory model is the tool for decision making even in complex conditions. In view of the generalization of the game theory model, we can replace Instagram by another social networking site say Twitter[18], LinkedIn etc. The common features of the respective competitor can be the base of interaction among them.

\section{REFERENCES}

1. A. Whiting and D. Williams, "Why people use social media: a uses and gratifications approach", Qualitative Market Research, vol. 16, no. 4, August 2013, pp. 362-369.

2. Eric W.T. Ngai, Spencer S.C. Tao, Karen K.L. Moon, "Social media research: Theories, constructs, and conceptual frameworks", International Journal of Information Management, vol. 35, issue 1, February 2015, pp. $33-44$.

3. N. Kwatra (2018, August 27),"Why Instagram has become the next Facebook". Available: https://www.livemint.com/Companies/MAEImnLVCnNqCntNtk31AJ/W hy-Instagram-has-become-the-next-Facebook.html

4. J. Pokrop, (2019, June 5), "Facebook and Instagram users in India". Available:

https://napoleoncat.com/blog/facebook-and-instagram-users-in-india/

5. M. Haigh, P. Brubaker and E. Whiteside, "Facebook: examining the information presented and its impact on stakeholders", Corporate Communications: An International Journal, vol. 18, no. 1, 2013, pp. 52-69.

6. H. Ting, W. W. P. Ming, E. C. de Run and S. L. Y. Choo, "Beliefs about the Use of Instagram: An Exploratory Study", International Journal of Business Innovation and Research, January 2015, pp.15-31.

7. Junyong In and Sangseok Le, "Statistical data presentation", Korean Journal of Anesthesiol, vol. 70, issue 3, June 2017, pp. 267-276.

8. Vincent P. Crawford, Introduction to Experimental Game Theory, Elsevier Science-Journal of Economic Theory 104, 2002, pp.1-15.

9. A. Baniak and Igor Dubina, "Innovation analysis and game theory: A review", Journal of Innovation: Organisation and Management, vol. 14, issue -2, Published online: 17 Dec. 2014, pp. 178-191.

10. L. Muggy and J. L. H. Stamm, "Game theory applications in humanitarian operations: a review", Journal of Humanitarian Logistics and Supply Chain Management, Vol. 4 No. 1, May 2014, pp. 4-23.

11. Z. Yurynets, R Yurynets and T. Gutor, "Game Theory Model for the Development of Optimal Strategy Towards Innovative Products Manufacturing at the Enterprise", Journal of Problems and Perspectives in Management, Volume 15, Issue 3, 2017, pp. 285-294.

12. W. Schumm, K. Pratt, J. Hartenstein, B. Jenkins, and G. Johnson, "Determining statistical significance (alpha) and reporting statistical trends: controversies, issues, and facts", Comprehensive Psychology Journal, vol. 2, January 2013, pp. 1-6.

13. D. Bonett and T. Wright, "Cronbach's alpha reliability: Interval estimation hypothesis testing, and sample size planning", Journal of Organisational Behavior, vol. 36, issue 1, January 2015, pp. 3-15.

14. Bolarinwa O.A., "Principles and methods of validity and reliability testing of questionnaires used in social and health science researches", Niger Postgrad Medial Journal, vol. 22, 2015, pp.195-201.

15. T. R. Soron and M. A. Tarafder, "The Relation between Facebook Use Pattern and Demographic Factors", Journal of Psychiatry, vol. 18, issue 5, September 2015, pp.1-5.

16. H.C. Chen and N.S. Wang, "The Assignment of Scores Procedure for Ordinal Categorical Data", The Scientific World Journal, Sept. 2014, pp. $1-7$.

17. P. Mishra, C Pandey, U Singh and A. Gupta, " Scales of Measurement and Presentation of Statistical Data", Journal of Annals of Cardiac Anaesthesia, vol. 21, issue 4, October 2018, pp. 419-422.
18. Said A. Salloum, Mostafa Al-Emran , Azza Abdel Monem, Khaled Shaalan, "A Survey of Text Mining in Social Media: Facebook and Twitter Perspectives", Advances in Science, Technology and Engineering Systems Journal, vol. 2, issue 1, January 2017, pp. 127-133.

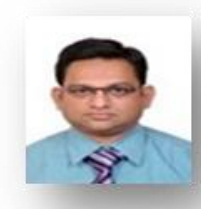

\section{AUTHORS PROFILE}

Satyajit S. Uparkar is working as Assistant Professor in the Department of Computer Application, Shri Ramdeobaba College of Engineering and Management, Nagpur. He is a triple post graduate and expert in the domain of data analytics. His research area includes Data Mining and Operation Research Modeling.

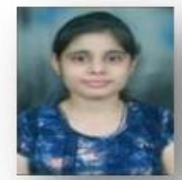

Khushbu R. Asati is MCA final year student at Shri Ramdeobaba College of Engineering and Management, Nagpur. Her area of interest includes Business Analytics and Machine Learning.

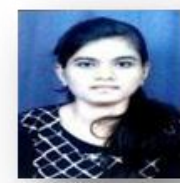

Prachi U. Sahahare is MCA final year student at Shri Ramdeobaba College of Engineering and Management Nagpur. Her area of interest includes Business Analytics and Machine Learning.

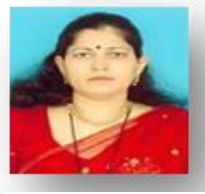

Nalini V. Vaidya is working as Assistance Professor in Mathematics Department, G. H. Raisoni College of Engineering Nagpur. She has completed her Ph.D. in Operation Research in 2016 from RTM Nagpur University and M.Sc. in Statistics also M.Ed from RTM Nagpur University, Nagpur, India. 